approach by encouraging the recognition and shared care of such patients.

Bethlem Royal Hospital

Monks Orchard Road

Beckenham

Kent BR3 3BX

SIR: At Oslo City Hospital (Ullevål Sykehus) we are in the process of establishing a liaison psychiatric service to the obstetric unit. The service is provided by the child psychiatry liaison team rather than the adult psychiatrists, who instead respond to specific referrals from the child psychiatric team.

The prime aim is to facilitate parent-child adaptation to each other. This is based on a recognition that factors in both mother and child, and in the marriage, affect early interactions-and especially that the several factors play upon each other. With this primarily 'preventive' orientation, consultation has another angle to it that is missing when referrals are primarily of the mothers, as to an adultorientated service. There is a reduced expectation of antenatal referrals, although these have been discussed with us.

The time is ripe to establish discussion between adult and child psychiatrists and their obstetrician colleagues about the directions for further developments in this field.

Department of Child Psychiatry

Simon R. WiLKINSON

Oslo Kommune

Ulleval Sykehus

0407 Oslo 4

Norway

\section{Practical administration of ECT}

SIR: The recent publication by the ECT SubCommittee of the Research Committee (Freeman et al, 1989) is a welcome step towards unifying the practice of this useful, if ill-understood, treatment. I was especially pleased to see recognition of the nursing responsibilities involved (Appendix 15).

I am, however, surprised to find the recommendation that simple observation is probably sufficient for the routine monitoring of fit length. Christensen \& Koldbak (1982) found no predictable relationship between EEG manifestations and the observed seizure duration (OSD), and bifrontal single channel EEG tracings are fraught with interpretive difficulties (Brumback, 1983). However, when the comparatively simple cuff technique was used during administration of ECT then OSD did correlate with EEG activity, although with shorter recorded seizure times (Fink \& Johnson, 1982).

At this centre, OSD is routinely recorded using the cuff technique to assist with the evaluation of individual treatment progress. There is a need for formal recording within ECT departments to facilitate both within-unit and between-unit review. $A$ brief study of inter-rater reliability of OSD is being conducted here, with a view to establishing the usefulness of its contribution in this area.

Postgraduate Office

Carl S. Littlejohns

North Wales Hospital

Denbigh

Clwyd LL16 5SS

\section{References}

BRUMBACK, R. A. (1983) EEG monitoring of ECT. British Journal of Psychiatry, 142, 104-105.

Christensen, P. \& Koldbex, I. B. (1982) EEG monitored ECT British Journal of Psychiatry, 141, 19-23.

FinK, M. \& JoHnson, L. (1982) Monitoring the duration of electroconvulsive therapy seizures. Archives of General Psychiatry, 39, 1189-1191.

Freeman, C., Crammer, J. L., Deakin, J. F. W., el al (1989). The Practical Administration of Electroconvulsive Therapy (ECT). London: Gaskell.

\section{Haslam's schizophrenics}

SIR: I applaud Persaud \& Allderidge (Journal, May 1989, 154, 719-720) for drawing Dr Hare's attention to John Haslam's published descriptions of schizophrenics. I would, however, dispute their assertion that the writings of Haslam suggest that schizophrenic symptoms were nothing new, or so common that they were hardly worth mentioning. In fact, in a series of 29 Bethlem case histories (Haslam, 1798), only one is described as experiencing auditory hallucinations. Haslam did devote a whole book to the study of a patient, James Tilly Matthews, with clear symptoms of schizophrenic thought disorder (Haslam, 1810), but the very title of the book, which begins Illustrations of Madness: Exhibiting a Singular Case of Insanity ... does not suggest that the patient's symptoms were common, obvious, or hardly worth mentioning at all. Indeed, Thomas Monro, Haslam's immediate superior as Physician to Bethlem, was in no doubt as to the 
unusual and florid nature of Matthews' symptoms: "having scarcely in the whole period of his professional practice and experience known any patient more completely and equivocally mad" (Monro, 1809). Haslam's clinical descriptions of his patients are noted for their clarity and keenness of detail, and he would not have failed to record the symptoms of schizophrenia if he encountered them.

The Maudsley Hospital

Denmark Hill

London SE5 8AZ

\section{References}

Haslam, J. (1798) Observations on Insanity, with Practical Remarks on the Disease, and an account of the Morbid Appearances on Dissection. London: F. and C. Rivington.

- (1810) Illustrations of Madness: Exhibiting a Singular Case of Insanity, and a No Less Remarkable Difference in Medical Opinions; Developing the Nature of Assailment, and the Manner of Working Events; with a Description of the Tortures Experienced by Bomb-Bursting, Lobster-Cracking, and Lengthening the Brain. London: G. Hayden.

Monro, T. (1809). Deposition of Dr Thomas Monro. Bethlem Archives, Box 60(8).

\section{Compulsive water drinkers}

SIR: Lee et al (Journal, April 1989, 154, 556-558) describe the case of a 16-year-old Chinese girl with water intoxication following the ingestion of large quantities of water for traditional medicinal purposes. I was surprised to read the suggestion that the use of water to induce an altered state of consciousness (ASC) had not previously been described. Many of the patients I have seen with excess fluid intake present as 'drunk'; intoxication is defined in most dictionaries as including a feeling of excitement, exhilaration, and inebriation. Perhaps the usual description of the symptoms of water intoxication does not include pleasure as this is not something the patient complains about. The literature does contain references to ASC, though this title is not used. For example, Singh et al (1985) describe how Case 1, on becoming unemployed and thus no longer able to afford alcohol, turned to regular excessive water drinking because it "made him feel slightly drunk" (this paper is quoted by Dr Lee et al). In a more recent paper on the possible association between water intoxication and alcohol abuse, Ripley et al (1989) write that "mild overhydration may be experienced as pleasurable, leading to further polydipsia".
With regard to the case described, the authors make no mention of the girl's tobacco smoking habits, although they acknowledge that the clinical picture suggests a degree of SIADH (syndrome of inappropriate antidiuretic hormone secretion). Nicotine stimulates the release of arginine vasopressin, and thus may be significant in the aetiology of water intoxication and SIADH. Other associated factors in SIADH (according to Singh et al) are stress, head injury, medications (antipsychotics, anticonvulsants, diuretics, and anti-cancer drugs), and various medical conditions (especially malignancies).

If, as the authors imply, drinking large quantities of water is a culturally accepted practice in traditional Chinese medicine, I wonder if this girl's complications are unusual, and if so, why she specifically was so adversely affected.

The seeking of an ASC may be an aetiological link in a proportion of compulsive drinkers. It is not, however, a 'missing' link.

Substance Abuse Service

JOHN A. COONEY

Alberta Hospital Ponoka

Alberta

Canada TOC $2 \mathrm{HO}$

\section{References}

Ripley, T. L., Millson, R. C. \& Koczapski, A. B. (1989) Selfinduced water intoxication and alcohol abuse. American Journal of Psychiatry, 146, 102-103.

Singh, S., PAdi, M. H. \& Bullard, H. et al (1985) Water intoxication in psychiatric patients. British Journal of Psychiatry. 146, 127-131.

\section{Risk factors in schizophrenia}

SIR: In their elegant study Baron \& Gruen (Journal, April 1988, 152, 460-465) found a greater familial risk for schizophrenia and schizophrenic spectrum disorders among probands born in the winter and spring than among those born during the remainder of the year. This finding is not in line with the major part of the pre-existing literature (Torrey, 1987), which primarily indicates an opposite trend. Aside from the results, the study also differs from previous ones in that it also considers the specific morbidity risk in first-degree relatives. In light of these discrepancies, we undertook a study to confirm whether schizophrenics born between December and April differ from those born during the other months of the year, both in relation to incidence of a family history of schizophrenia and to a familial morbidity risk for 